\title{
Teologia y secularización de las virtudes en el Concilio Vaticano II
}

La teología, después del Vat. II, ha recuperado aquella unidad inicial y radical de que disfrutaba en los comienzos de la reflexión patrística. La sistematización de la teología en el ámbito de las ciencias a partir del humanismo nos ha entregado una teología aparentemente fragmentaria, dividida o compuesta de tratados, de sectores de reflexión a los que no se les veía fácilmente una unidad integrante. Después de un período de disgregación científica en la teología con enormes deseos analíticos, nos dirigimos actualmente hacia una convergencia de los diversos sectores teológicos; una convergencia y una integración que no nos privará de la correspondiente comprensión total de todas y cada una de las exigencias que nos lleguen de diversos puntos problemáticos. "Es preciso aprender a vivir bajo la presión de las tensiones teológicas... Sin duda las disciplinas se desarrollan hacia una nueva forma de unidad de la teología que será distinta de la actual y que por el momento no nos es posible anticipar en sus perfiles concretos)" ${ }^{3}$.

Lo importante es que los alumnos vayan penetrando cada vez más en esa unidad radial de la verdad teológica. La verdad, el espíritu, no crece por extensión; ni siquiera por ampliación de sus objetos; crece en profundidad de penetración y clarividencia unitaria de la

1. Cfr. E. NEUHAUSLER - E. GOSSMAN: Qué es teologla? Salamanca 1969; pp. 528-529. Ese cambio en la teología ha venido motivado por el abandono de la orientación metafisica en la forma de presentarla y de estudiarla y verla ahora como una historia de la salvación más unitaria y correlativa entre sí. Cfr. etiam R. LAUTOURRELLE: Teología, ciencia de la salvación. Salamanca 1968; W. KASPER: Unidad y pluralidad en teologia, Salamanca 1969; H. FRIES: Conceptos fundamentales de teología, 4 vols. Madrid 1966-67; C. COLOMBO: La metodología e la sistematione teológica, en el vol. "Problemmi e Orientamenti di Teoloaia dommatica" I. Milano 1957; A. KOLPING: Enfürung in die katholische Theologia, Müstor 1960;; IDEM: Katholische Theologie gestern und heute, Bremen 1964; M. J. LE GUILLON: Teología del misterio, Barcelo-
na 1967. 
verdad. Eso mismo pasa en teología: la madurez teológica deberá medirse por esta capacidad de unificar radialmente los distintos aspectos de tal reflexión y penetrar más claramente, más intensamente en el contenido indivisible de la teología que hoy se denomina con la expresión de historia de salvación o misterio de Cristo, y que ha venido a demostranos esa trabazón interior que tienen todos los núcleos de reflexión teológica, en un sentido histórico-existencial y cristiano.

El Concilio, como decíamos, ha sarvido a esta integración de la teología dando así un carácter unitario a toda ella. Pide y desea esa unión en su Decreto sobre la Formación sacerdotal, n. r6: "Aprendan además los alumnos a aclarar en cuanto sea posible los misterios de la salvación, a comprenderlos más profundamente y a captar sus mutuas relaciones por medio de la especulación". Y en el n. I7: (Procúrese diligentemente la unidad y solidez de toda la formación). Estas son las llamadas del Concilio a la unidad en la teología y en sus distintas disciplinas; y toda ella en función del misterio de Cristo y de la historia de salvación ${ }^{2}$.

Nuestro propósito en este trabajo es desarrollar la visión dejada por el Concilio acerca de lo que en teología se llama las virtudes teologales. Es una orientación bien definida y aprovechable para ensanchar los reducidos límites y simpatías que mantenía este tratado en nuestra teología tradicional, hecha evidentemente a base de datos tomistas que sofocaban especialmente aquí los datos bíblicos y patrísticos. También la renovación tiene que llegar a este sector un poco abandonado: el de las virtudes y su función en la configuración de la teología. Nosotros estimamos que tal como van poniéndose las cosas en la situación de la teología que anda en busca de sí misma, de su identidad con el hombre de nuestro tiempo; que se encuentra en una situación dialogal con la fenomenología, con la antropología; que se está incorporando las visiones existenciales del hombre de hoy sobre sí mismo, pensamos oue el tratado o la reflexión teológica sobre las virtudes tiene una palabra decisiva en este compromiso de la teo-

2. Existen ya bastantes estudios sobre esta tarea que le viene impuesta a la teología por el Concilio mismo: cfr. especialmente B. LAMBERT: Les deux démarches de la theologle, en "Nouv. Rev. Theol." 89 (1967) 257-280; M. NEDONCELLE: Teología y filosofía o las metamorfosls de una sierva, "Concilium" 6 (1965) 97-108; K. RAHNER, De la formación teolónica de los futuros sacerdotes, en el vol. "Misión y gracia" II. S. Sebastian 1968; 89-118; G. BALDANZA: II rinnovamento deali studi filosofici e teologici nei Seminari, "La Scuola cattolica" supl.2 (1956) 83-146; L. WALTERMANN: Klêrus zwischen wesenschat und Seelsorger. Zur Reform der Priesterausbildung, Essen 1966; cfr. etiam el número extraor. de la Rev. "Seminarium" 19 (1967). 
logía de abrirse más al mundo y al hombre de nuestros días. Entre las posibles opciones de la teología, esta convergencia de sus temas en el homb:e favorece enormemente las posibilidades de incorporar las virtudes teologales a una penetración del misterio del hombre a la luz del misterio de Dios. Y lo mismo sucede en un ámbito cósmico: también las virtudes ayudarán a comprender la visión conciliar y teológica del mundo actual en actitud de esperar un servicio de la Iglesia y del cristianismo a través de los cristianos. Esto lo harán ellos a través de sus virtudes que serán posturas existenciales concretas del cristiano frente a los acontecimientos y frente a los tiempos y su significación salvífica. La teología de hoy que se está haciendo bajo el signo del hombre, del servicio, de la totalidad cósmica y del diálogo tiene necesariamente que preocuparse de una revalorización conveniente de este sector que es la reflexión sobre las virtudes teologales con sus dinamismos $y^{\prime}$ repercusiones adyacentes.

Pero aquí nos asalta y nos espera una dificultad. Se ha dicho y se ha escrito por uno de los autores del Concilio que "el estilo teológico del Concilio está lejos de corresponder al lenguaje del porvenir ya comenzado" ${ }^{3}$. Si esto es verdad yo no lo sé; pero lo que sí podemos saber es que, si esto es verdad, es inútil una teología del Concilio y una teología desde el Concilio. Estamos perdiendo lamentablemente el tiempo y en vez de dedicarnos a reflexionar sobre el Vaticano II lo que teníamos que hacer era convocar ya el Vaticano III, pero rápidamente, no sea que lleguemos ya tarde para coger (un porvenir ya comenzado" que nadie sabe cuándo va a comenzar y cuándo va a dejar de ser porvenir.

Todavía existen expresiones más fuertes en torno a esta inutilidad del Concilio que nos colocan frente a un grave problema del desplazamiento teológico en aue so mueve la Iglesia. Esta vez las afirmaciones son de un saglar: «El Concliio fue ciertamente demasiado tradicional, en su forma, todavía demasiado cerradamente clerical y demasiado cerradamente teológico-profesoral en su lenguaje. El Concilio manifestó una preocupación -mantenida todavía hoy mismopor subrayar la inmutable continuidad de la doctrina católicas ${ }^{\wedge}$. Esto sí que no es verdad. Es lamentable que se diga todo esto de un

\footnotetext{
3. Cfr. estas palabras $y$ otras reflexiones en K. RAHNER: Teologia $y$ ciencias naturales, Taurus, Madrid 1968; pról.

4. J. L.. ARANGUREN: Crisis del catollolsmo, Madrid 1969. En esta linea de pesimismo están también: A. ADOLFS: La tumba de Dios, Buenos Aires 1968.
} 
Concilio. Yo no sé que podían esperar estos autores de un Concilio al que le quieren atribuir un lenguaje profético a largo plazo, como si el tiempo no fuese una categoría esencial de lenguaje y de pensamiento.

El Concilio no fue demasiado tradicional ni en su forma ni en su contenido. Tenemos muchas razones para pensar así. ¿Cuál sería una forma no tradicional de hablar un Concilio? ¿Se ha pensado por ejemplo en lo que significa que un Concilio hable de los medios de comunicación social, de las relaciones de la Iglesia con el mundo contemporáneo, de la libertad religiosa, del apostolado de los seglares, del ecumenismo, del matrimonio, de la natalidad, de la cultura, de la paz, de la guerra, del hambre, del trabajo, del desarrollo? ¿Se puede decir honestamente que el Concilio y la Iglesia de hoy es notablemente escasa en referencias a los problemas aue angustian a la humanidad contemporánea cuando el Concilio ha significado precisamente un encuentro benéfico en forma y fondo de la Iglesia con el mundo de nuestros días? ¿Es lícito seguir pensando que el tono y el lenguaje del Concilio sobre estos temas y del Magisterio pontificio posterior es cerradamente clerical y profesoral cuando vemos que una gran parte de los documentos conciliares están ocupados por las relaciones de la Iglesia con la humanidad? ¿Es que acaso los problemas de esa humanidad, a la que hay que hablar, sólo se limitan a problemas de política, de urbanismo y de sociología? Tampoco se puede tachar, con ligere$\mathrm{za}$, al Concilio de ser tradicional y de no preocuparse más que de conservar lo decidido, lo dado, lo recibido sin abrir más cauces nuevos a la vida de la Iglesia en un nivel doctrinal y pastoral. Lo reconoce más adelante el mismo autor del que hablamos ${ }^{5}$. Pero ya podía haberlo reconocido primero y haberse ahorrado expresiones tan poco exactas como las anteriores. Desde un principio el Concilio se preocunó de las dos cosas que tenía que preocuparse: de ser continuación y novedad; de exponer claramente lo que hay de cierto, de ortodoxo, de verdadero en la Iglesia y de exponerlo de forma que lo entiendan los hombres de hoy: dialéctica de continuidad y de renovación.

$A$ veces pienso que se pide al Concilio lo que no puede hacer y

5. J. L. ARANGUREN: op. cit. pág. 26-27: “Pero el Concilio -escribe- ha creado una nueva situación, ha abierto una nueva etapa aue se puede ciertamente frenar pero desde la aue no se puede volver atrás porque es irreversible; y ha proporcionado una nueva plataforma para las reformas ulteriores". El mismo Aranguren no está satisfecho con el término "aggiornamento": le parece insuficiente. 
lo que ha hecho la llamada teología radical: un cambio y una renovación no sólo en la presentación de la fe sino en el mismo concepto y realidad de la fe; sería una especie de ateísmo cristiano porque sería dar muerte a la fe tradicional y dar vida a un nueva fe; a un nuevo Dios ${ }^{6}$.

Nosotros vamos a intentar esa laudable tarea de no frenar las energías suscitadas por el Concilio en el seno de la reflexión teológica y vamos a aplicar sus nuevas perspectivas a ese olvidadizo tratado o sector que llamamos, ahora sí que con terminología profesoral, académica, de las virtudes teologales; o lo que es lo mismo: lo que dice el Concilio sobre la fe, la esperanza y la caridad en la vida actual del cristiano, de la Iglesia como realidades que están viviendo situaciones en cierto punto nuevas frente a un mundo también nuevo, parcialmente cambiado en su configuración religiosa. Pero en seguida constataremos que no es precisamente en un tono escolástico (de escuela), de cátedra, como habla el Concilio sobre las virtudes; sino que es en una dimensión más asequible, más vital, más a la altura de nuestras necesidades cristianas y eclesiales.

También aquí se cumplen las palabras que Pablo VI ponía como jalones del Concilio, por lo menos en su terminación, en su finalidad: "Quisiéramos, finalmente, que la doctrina de la Iglesia irradiara también con algún reflejo de atracción, al mundo profano en el que vive y del que está rodeada... Como todos pueden observar, la elaboración de esa doctrina, ateniéndose al rigor teológico que la justifica y la engrandece, no se olvida nunca de la humanidad que se da cita en la Iglesia o que constituye el ambiente histórico v secial n que se desarrolla su misión. La Iglesia es para el mundo... La Iglesia perfeccionando su pensamiento y su estructura no trata de apartarse de la experiencia propia de los hombres de su tiempo, sino que pretende de una manera especial, comprenderlos mejor, compartir mejor con ellos sus sufrimentos y sus buenas aspiraciones, confirmar el esfuerzo del hombre moderno hacia su prosperidad, su libertad y su paz) ?

\footnotetext{
6. Si a veces y algunos ha defraudado el concilio es porque esperaban o tenian de él una idea menos real. La finalidad y utilidad del concilio está asegurada en la medida que responde a las intenciones de quien lo convocó, no en cuanto satisface a los deseos de algunos grupos ideológicos concretos.

7. PABLO VI: Discurso pronunciado el 21-X|-1964 en la sesión de clausura de la 3. a etapa conciltar (Cfr. Concillo Vaticano II. Constituciones. Decretos. Declaraciones. B. A. C. Madrid 1965; pp. 792 ss.); J. MORAN. El hombre y los valores humanos en el Concillo Vaticano II, "Arch. Teol. Agust." i (1966) 87-114.
} 
PRESUPUESTOS DOCTRINALES

\section{PARA ENTENDER EL CONCILIO.}

No es afortunado ir directamente a conocer la doctrina conciliar sobre un determinado punto de la teología sin conocer previamente las tensiones histórico-doctrinales en que se desarrollaba tal reflexión en el contexto total de la teología católica e incluso de la teología protestante, que muchas veces sirve de fondo de convergencia para algunos planteamientos.

La teología, a la llegada del Concilio, estaba superando fatigosamente su planteamiento tradicional en fórmulas racionales, un poco apriorísticas, y ya se estaba dibujando una teología mucho más bíblica, salvífica y existencial. El Concilio viene considerado como un espacio de resonancia de todas las mentalidades teológicas simultaneamente enfrentadas y comprometidas en elaborar unas fórmulas de síntesis y de reconciliación. En este intento es donde el Concilio, para unos se ha quedado corto, para otros ha significado ya un avance sin riesgos, evidentemente.

Algunos hubiesen deseado que el Concilio fuese una especie de teología radical católica que imitase los cambios radicales que se han dado en la reflexión protestante. Ello significaría un cambio en los planteamientos tradicionales de la teología para alumbrar un nuevo modo de hablar de Dios: inauguración no sólo de nuevas fórmulas sino de nuevos conceptos; no bastaría un lenguaje nuevo sino que 'hacía falta unos contenidos nuevos. Por eso desilusionó mucho la fórmula de trabajo y de orientación que Juan XXIII señaló al Concilio: renovación en la continuidad, no contra la continuidad, contra lo decidido: "Lo que principalmente atañe al Concilio ecuménico es esto: que el sagrado depósito de la doctrina cristiana sea custodiado y enseñado en forma más eficaz... El Concilio ecuménico quie. re transmitir la doctrina pura e íntegra sin atenuaciones que durante XX siglos a pesar de dificultades y de luchas se ha convertido en patrimonio común de los hombres... Nuestro deber no es sólo custodiar ese tesoro precioso como si únicamente nos ocupásemos de la antigüedad, sino también dedicarnos, con voluntad diligente, sin temores a la labor que exige nuestro tiempo prosiguiendo el camino que la Iglesia recorre desde hace XX siglos. Si la tarea principal del Concilio fuese discutir uno $\mathrm{u}$ otro artículo de la doctrina fundamental 
de la Iglesia, repitiendo con mayor difusión la enseñanza de los $\mathrm{Pa}$ dres, de los teólogos antiguos y modernos, que suponemos conocéis y que tenéis presente en vuestro espíritu, para esto no era necesario un Concilic. Sin embargo de la adhesión renovada, serena y tranquila a todas las enseñanzas de la Iglesia, en su integridad y precisión... el espíritu cristiano, católico, y apostólico de todos espera que se dé un paso adelante hacia una penetración doctrinal y una formación de las conciencias que esté en correspondencia más perfecta con la fidelidad a la auténtica doctrina, estudiando ésta y poniéndola en conformidad con los métodos de la investigación y con la expresión literaria que exigen los métodos actuales» ${ }^{8}$.

Ahí tenemos, pues, la dialéctica doctrinal en que se coloca el Concilio: una afirmación o reafirmación de lo que ya la Iglesia ha vivido, conquistado, conseguido durante tanto tiempo y tantos esfuerzos en el orden doctrinal y en el orden pastoral; pero al mismo tiempo, un movimiento constante de renovación, de creación de nuevos pasos, de nuevos métodos teológicos, de nuevos estilos de pensar y vivir según las nuevas modalidades del mundo moderno. Hasta qué punto el Concilio ha hecho una nueva teología, no será fácil juzgarlo de cerca, con exactitud. Tendremos que esperar todavía para apreciar mejor lo aue ha significado de cambio, pequeño o grande, en la consolidación de nuevos caminos para la teología de siempre. Lo importante es admitir aue el Concilio fue una irrubción nueva en la teología que condiciona en ella nuevas exigencias de reflexión, de planteamiento, de respuestas más comprometidas. Ya se ha hecho algo en este sentido y tenemos que continuar haciéndolo ; porque en tanto somos fieles al Concilio en cuanto estamos permanentemente atentos a adaptar nuestras formas de pensamiento, y el pensamiento mismo, a las situaciones nnevas de la humanidad. Y todo ello, aunque se parta de posiciones fijas e invariables que hunden sus raíces en un pasado histórico-teológico. No hay oposición entre fidelidad a un pasado permanente y atención a un presente nuevo. No hay oposición entre una teología recibida y una teología por hacer; y no es necesario nue ésta suria de las cenizas de aruella. El Concilio no enterró nada tel pasado sino que lo asumió y lo incorporó, cargado de nuevas

8. Discurso pronunciado por Juan XXIII el 11-X-1962 en la solemne inauquración del Concillio Vatirano II (Cfr. Concilio Vaticano II. Constituciones. Decretos. Declaraciunes. B. A. C. Madrid 1965: pp. 748-749. 
perspectivas, y lo entregó a la Iglesia de hoy para que lo presente a un porvenir ya comenzado.

\section{TEOLOGIA DEL CONCILIO Y SECULARIZACION.}

Ia nueva situación en aue estamos viviendo ya tiene un nombre: sscularización. Tiene también razones y justificaciones. El dualismo y el enfrentamiento tradicional que algunos atribuyen a un cristianismo platónico, entre religión y vida, tzología y realidad, espiritualidad y situaciones terrenas va camino de converger en la nueva reflexión sobre la secularidad cristiana. Sin embargo el término y la realidad de la secularización todavía va encontrando mucha resistencir: Hay cristianos oue sa alarman ante este fenómeno. Les parece como si la secularización hubiese de firmar la sentencia de muerte contra el cristianismo. En este caso no le quedaría al cristianismo más que esta alternativa: o detener la secularización o declararse vencido ") . Ninguna de estas alternativas es posible: la única opción es construir una secularización cristiana o, si ello es lo mismo, cristianizar la secularización. Esto que tiene lugar en los niveles pastorales, dinámicos, de roce, en la Iglesia, tiene que tener lugar también en los niveles de teología. No hay que hablar tanto de la teología de la secularización sino de la secularización de la teología cuyo ensayo tenemos ya en el Concilio, aunque no haya satisfecho las aspiraciones de algunos en su proceso secularizador ${ }^{10}$. La secularización no necesita quizá de la teología sino viceversa : la teología necesita de la secu-

9. Cfr. R. CASTAÑEDA: Mundo y fe en evolución radical. Las estructuras revolucionarias del proceso de secularización eclesial, Madrid 1970, 7. Habla también de la "nueva metodología" impresa por el Concilio a la Teología (pág. 10-11) basado precisamente en la "Gaudet. spes". Cfr. etiam B. HARING: A modo de conclusión, en el vol. col. "La Iglesia en el mundo de hoy". Estudios y comentarios a la Const. Gaud. et spes del Conc. Vat. II (Obra dirigida por G. Barauna) Madrid 1967, 686: "Como clara perspectiva para la teología de la época posconciliar llega a cristializar teniendo muy en cuenta las discusiones y el fruto verdaderamente pastoral de la Constitución sobre la divina revelación, esta actitud más consciente: la teología ha de considerar todos los documentos históricos, incluso la Sda. Escritura como una palabra de verdad y salvación dirigida a cada momento histórico del destinatario y de sus aspiraciones. Las formulaciones de siglos pasados las ha de despojar la telogía de sus elementos ambientales de origen y traducirlas a las circunstancias de nuestros tiempos atendiendo a lo permanente y teniendo en cuenta amorosamente a los hombres de nuestra época son su peculiar sen sibilidad... Quien no quiere tomarse la molestia de distinguir la verdad permanente y. el mensaje salvífico de su ropaje, de los elementos ambientales, adultera la doctrina.

10. Efectivamente: tenemos ya muchos estudios que justifican una teología de la secularización, pero son menos los ensayos dedicados a justificar una secularización de la teología que no es lo mismo, si no en sí misma por lo menos en sus métodos. Cfr. R. RICHARD: Teologia de la secularización, Sigueme Salamanca 1969; A. AUER: Sekularisierung, en "Lexik. Theol. und Kirche" IX Freiburg im Br. 1964; M. CASTER: La seculrisation interpretée dans une perspective chretienne "Lumen vitae" 23 (1968) 445-463; A. DURAND: Secularisation et sens de Dleu "Lumiére et vie" 89 (1968) 61-85; L. MALDONADO: La nueva secularidad, Barcelona 1968; L. NEW-

BIGIN: Religión auténtica para el hombre secular, Bilbao 1968. 
larización. Cuando Sto. Tomás se encontró con la filosofía aristotélica como mentalidad de su tiempo, no se dedicó a hacer una teología del aristotelismo; no puso la teología al servicio de una expresión filosófica de su tiempo sino que emprendió la ejemplar tarea de poner la fórmula de una filosofía secular al servicio de la teología permanente. Algo de esto tenemos que realizar nosotros, los responsables de dar una expresión (mundana) a todo el cauce teológico que está formado por los contenidos de siempre que se han obtenido e incorporado a lo largo de toda la historia de la reflexión teológica.

Leemos en un libro reciente: "Si la nueva vida de fe significa un abandono definitivo del dualismo y del espiritualismo, una de las consecuencias más importantes que de aquí se deducen es la valoración positiva y la realización consiguiente de la secularización. Vivimos en un período expresamente orientado hacia lo secular) ". abandono del espiritualismo y del dualismo de que se habla aquí afecta, evidentemente a toda la teología y a sus sectores más importantes. Afecta, en primer lugar a la visión del problema de Dios y exige un nuevo planteamiento del modo de "llegari) o de concebir a Dios. No es que haya que cambiar y sustituir un Dios por otro como quieren los teólogos de la muerte de Dios. Pero lo que realmente tiene que preocuparnos es estar constantemente atentos a la forma cómo quieren nuestros contemporáneos que se les hable de Dios y revisar, en función de ello, nuestra teología, es decir, nuestro discurso de Dios e ir en busca de un Dios penetrante. Dios está costando mucho a la teología: "Si estamos viviendo el fin del cristianismo convencional la problemática se centra especialmente en el tema de Dios) ${ }^{12}$. También

11. H, FIOLET H. VAN DER LINDE: Fin d 1 cristianismo convencional. Nuevas perspectivas. Salamanca 1969; p. 17. Sabido es cómo este libro es la reacción favorable por lo general de un grupo de autores a la obra anterior de W. VAN DE POL: La in du christinisme conventioneel, Ed. Centurion, Pris 1968 (el original es en holandés) donde también se plantea este problema; pero el autor se inclina a llamar a este proceso de secularización, de renovación y revolución. algo ecuménico que afecta a todas las concepciones de la fe; "Asistimos al fin, rápido pero definitivo, de un cristianismo viejo y convencional. El coloca a los cristianos de todas las Iglesias y de todos los horizontes ante una tarea común: la de dar a la fe y a la vida cristiana unas formas nuevas tales que en el mundo de mañana que se construye, el Evangelio pueda significar todavía una fuerza divina realmente capaz de edificar un mundo nuevo y de preparar la venida del Reino de Dios a todos los hombre de aquí abajo": pán. 14.

12. L. BAKKER: Tras el fin del cristian'smo convencional, en: FIOLET VAN DER LINDE: Op. cit. pág. 27. Hay mucha literatura con aire profético que habla va del nuevo cristianismo, del Dios del mañana frente al de ayer, de la Iglesia del futuro, de la nueva fe, de la nueva religión, etc. Son todos esfuerzos en tensión de profecia y descubrimiento del concepto y de la vivencia de Dios, de la fe, de lo sobrenatural, que nadie sabe cómo será. Cfr. por ei. además de Abscher vom Christentum, München, 1963; H. FESQUET: Le catholicisme, religlón de demain? Ed: Grosset; París 1962; VARIOS: Dios, hoy (XVII Semana de los intelectuales france- 
es verdad que Dios está condicionando toda la teología y cualquier opción de la secularidad ante el problema de Dios está ya exigiendo un correspondiente cambio en las demás realidades teológicas: Cristo, Iglesia, sacramentos, virtudes, etc. Todo lo sagrado, todo lo religioso viene sacudido por esta variación central que es el nuevo planteamiento del lenguaje sobre Dios y por tanto el nuevo planteamiento del sobrenatural con todos sus contenidos ${ }^{13}$.

La alternativa de la teología en este confrontamiento con la secularización en relación con el problema de Dios está clara: una vía media entre el dualismo que coloca a Dios fuera del mundo y el panteísmo. Una mayor aproximación de la trascendencia de Dios y de la intimidad de Dios: una convergencia de la realidad Dios y de la realidad mundo en la unidad de la experiencia religiosa que llamamos secularización. Habrá desaparecido la opción dualista: o Dios o el mundo y se irá hacia el encuentro de Dios en el mundo ${ }^{14}$.

Otro tanto está pasando con la visión del mundo. Son dos aspectos de un mismo problema : la visión teológica de Dios incide sobre la visión correspondiente del mundo. Son dos correlaciones. Lo que la secularidad está afirmando es aue no existe incompatibilidad entre una pertenencia a Dios por la fe y una pertenencia al mundo; que no hay oposición entre ser de Dics y ser del mundo; entre amar a Dios y amar al mundo; entre intimidad religiosa y proyección humana. La existencia en el mundo se convierte así en el encuentro con Dios; toda la realidad terrena (llamada profana) se convierte así en algo sagrado donde se realizan las mejores comunicaciones religiosas con Dios. Según esto la espiritualidad ya no insistirá en una renuncia al mundo sino en una apertura; ya no será una ascensión sino una encarnación. Veremos cómo todo esto está también condicionando la relación dinámica entre el

ses) Bercelona 1938; J. SUDBRACK: Atheismus als Modoll chistlicher fottesbegegnung "feist und Leben" 43 (1970) 24-38: L. DEWART: The future of Belief Theism in a World come of Age, New York 1966; J. HOEKENDIJK: Die Zukunft der Kirche und die Krche der Zukunft, Stuttgar 1965; A. HORTELANO: La Iglesla del futuro, Salamanca 1970:

13. Cfr. para todo el problema de Dios frente a la secularización. las reflexiones sobre "Dios en revisión" y "en busca del Dios vivo" de E. SCHILLEBEECK: Dios y el hombre, Salamanca 1969; pp. 15-56. Podemos señalar también U. VON BAL.THASAR: El problema de Dlos en el hombre actual. Guadarrama, Madrid 1966; K. RAHNER: Peligros en el catolicismo actual, Guadarrama, Madrid 1964.

14. En esta línea de pensamiento están: $O$. RABUT: Valor espiritual de to profano, BarceIona 1965; E. SCHILLEBEECKX: Refflexions sur I' Imane concil aire de I homme et du monde. en el vol. "L. Eglise dans le monde de cet temps" Paris 1967; P. ROQUEPLO: Experencia del mundo experencia de Dios. Salamanca 1969; J. B. METZ: Tenlnaía del mundo. Salamarica 1070. P. CREN: El cristlanismo y el mundo, en "Cnncilium" 19 (1966) 254-268; U. VON BALTHASAR: Ei encuętro con Dios en el mundo actual "Concilium" 18 (1965) 24-41. 
cristiano y el mundo que tendrá lugar en las virtudes dichas "teologales) ${ }^{15}$.

Otro punto que viene afectado por la secularización en esta secuencia de derivaciones es la cristología. El cristianismo tiene siempre su fundamento en la persona histórica de Cristo. Cualquier interpretación de Cristo revierte inmediatamente en la concepción del cristianismo. Y al contrario : cualquier cambio en el planteamiento de las actividades teológicas se apoya o intenta apoyarse en Cristo, en su configuración humano-divina. Para la secularidad toda la historia de salvación parte de un hecho bien concreto: Dios habla y sigue hablando por los acontecimientos de cada día. El acontecimiento central es Cristo, el Dios secular, el Dios hecho hombre. El Dios que asume todo lo humano y que vive lo humano de forma divina. Jesús es el prototipo de la secularidad cristiana porque en su ser humano vivió su relación integra con Dios y no construyó una religión separada) y abstracta. Jesús era simultáneamente, en un mismo acto existencial, Dios-hombre. Era un hombre secular viviendo para los demás hombres, y haciendo de este servicio la esencia de su misión (rreligiosa). Desde Cristo, todo acto de amor al mundo, a los demás, es en sí mismo simultáneamente amor a Dios que es el tercer trascendente en el proceso del amor a quien se dirige siempre el amor. La cristología está condicionando la inteligencia actual de la primacía y ordenamiento de las virtudes teologales, como tendremos ocasión de ver más adelante ${ }^{16}$. La fe vendrá desplazada hacia la caridad como centro del cristianismo de Cristo frente al cristianismo sin Cristo que habíamos hecho, según la secularidad. Porque Jesús es el ejemplar absoluto del empeño religioso y del compromiso ético que es el cristianismo. Cristo es la interpretación y vivencia religiosa, la unificación para siempre, de lo sagrado en lo profano, en lo

15. El tema se ha tratado mucho a partir de la llamada espiritualidad del laicado. Para una visión de esta antinomia, cír. K. W. TRUHLAR: Antinomias de la vda espiritual, Madrid 1964; pp. 89-142; H. SANSON: Espiritualidad de la vida activa, Barcelona 1964. También J. R. GARCIA MURGA: Intimidad con Dios y servcio al prójimo (A la luz de la teología de $K$. Ranher) Madrid 1970 .

Siguen siendo válidas las refiexiones de LILI ALVAREZ: En tierra extraña, Madrid, 8 ed. 1964: "Sin darnos demasiada cuenta nos encontramos ante un hecho capital en la historia de la conciencia religiosa y que sólo recientemente estamos empezando a vislumbrar, existen efectivamen te dos formas maestras y básicas de espiritualidad... Yo calificaria a la una de "ascendente" y a la otra de "descendente" (páa. 93).

16. Cfr. A. ALVAREZ BOLADO: Una cristologia sin Dios, "Razón y Fe" 852 (1958) 47-63; 179 (1969) 263-282. IDEM: La teologia americana de la muerte de Dios, en el vol. "Dios-Ateismo" (III Semana de Teologia) Bilbao 1968; pp. 299-374; E CASTELLI: El tiempo de la encarnación y el tiempo de la mundanidad. "Conicilium" 41 (1969) 59-66; L. MALDONADO: La nueva secularidad. Barcelona, 1968, 157-170; K. RANHER: Problemas actuales de cristologia, en "Escritos de Teología" I Madrid, 1959; pp. 169-223; IDEM: La cristología dentro de una concepción evolutiva del mundo, "Ibid" $V$ Madrid 1864; pp. 181-221. 
secular. "Lo sacro en la persona de Cristo es ahora el centro de lo profano y le confiere su orden, su unidad y su realidad más plena. Mediante el elemento profano de su cuerpo humano Jesucristo se ha insertado en nuestras vidas y en nuestro cosmos. $Y$ dado que este cuerpo humano murió y resucitó a una vida gloriosa y nueva, ese centro sacro sigue inserto en lo profano de nuestras vidas y de nuestro cosmos. Jamás dejará de ser el centro') ${ }^{17}$.

También la sacramentología adquiere una primacía en la vivencia del cristianismo actual orientado y comprometido en la secularidad. Todo es sacramento, es decir acontecimiento visible que lleva una religiosidad en sí mismo aunque no sea por sí mismo. Es una derivación de lo que decíamos sobre la interpretación actual de la historia de salvación y en especial sobre la estructura y función salvífica de Cristo, de quien recibe su sacramentalidad todo acontecimiento del mundo y de la historia. El cristianismo es un encuentro sacramental entre Dios y el mundo a partir del hecho profano que ya no es ni puede ser profano. Habrá que diferenciar los niveles de sacramentalidad. En el vértice de estos niveles están los sacramentos como punto de partida para una vivencia concreta del encuentro con Cristo que tendrá que significar la sacralización de todo lo que antes podría ser profano. Y en el plano de la piedad, de lo sobrenatural, de lo religioso, el primer lugar le tienen siempre los sacramentos seguidos de las virtudes que son ya para siempre "sacramentales» en doble sentido como veremos más adelante ${ }^{18}$.

Si este es el panorama de la secularización de la teología en estos momentos ¿cuál es, nos preguntamos, el puesto que tienen las virtudes en este proceso de la teología?

17. A. G. MALONY: El Cristo cósmico. De S. Pablo a Teilhard, Santander 1967; pág. 8. La cristología secular está, como apuntábamos, en el centro de la teología de las realidades terrenas que se va configurando lentamente. La aplicación se está haciendo al cosmos, al tiempo, a la historia, al trasajo, a la cultura etc. Cfr. los ensayos siquientes: J. MOUROUX: El misterio del tiempo Barcelona, 1965; M. BORDONI: Y tempo. Valore filosofico e misterio teologico. Roma 1965; O. CULLMANN: Cristo y el tlempo, Barcelona 1967.

18. Paradójicamente a lo que podría esperarse do la desacralización o de la desmitologización de la liturgia, derivada de la secularización, los sacramentos han venido revalorizados en la esencia del cristianismo. Será un proceso quizá inverso al tradicional: los sacramentos itúraicos como continuación de los sacramentos "profanos" que hay esparcidos por la realidad cósmica. Para la espiritualidad de los sacramentos cfr. K. RAHNER: Devoción personal y sacramental, en "Escritos de Teologia" II, Madrid 1961, pp. 115-141; VARIOS: Hor zontes del sacramento, núm. extr. de la Rev. "Liturgia" 24 (1969); J. M. O'CONNELL: The sacraments in Theology today. "Thaught" 36 (1961) 41-58; E. SCHILLEBEFCKX: Cristo, sacramento del encuentro con Dios. S. Sebastián 1964; J. F. LESCRAUWAET: l.a litrria y el sontimlento vital de hov. en el vol. "Fin del cristianismo convencional" Salamanca 1969; pp. 273-298; P. SMULDERS: Ei sacramento como acto de fe, "Ibid" pp. 321-340. 


\section{r. PERSPECTIVA TEOLOGICA EN LAS VIRTUDES}

Iglesia y mundo son las dos dimensiones de toda teología y reflexión conciliar. En algunos documentos estará más en primer plano la Iglesia; en otros estará el mundo; pero son siempre vertientes simultáneas de unos mismos conceptos; son siempre dos interlocutores invisibles del diálogo que es la teología del Concilio. El Concilio es - se ha dicho ya muchas veces- la reflexión de la Iglesia sobre su ser interno y sobre su ser hacia fuera, hacia el mundo que la rodea, que la mira, que la acecha y que la espera.

Vamos entonces a penetrar en un estudio de las virtudes teologales en el Vaticano II por esta perspectiva teológico-eclesial a que nos tiene acostumbrados en el enfoque de tantos sectores en la teología de hoy. Más adelante tendremos ocasión de prolongar esta pers. pectiva con otras de ámbito más dinámico y mundano, es decir: ahora vamos a ver las virtudes en el dinamismo del ser interno de la Iglesia y luego las veremos dentro de su dinamismo apostólico de cara al mundo.

\section{a) Iglesia y virtudes:}

Nos esforzaremos por encontrar el lugar que el Concilio concede a la trilogía fe-esperanza-caridad dentro de la teología de la Iglesia.

Todo parte del hecho genético de la eclesiología: El Padre iniciador del misterio eterno de salvación sobre los hombres comunicándoles su misma vida, envió a su Hijo al mundo para que fuera el primero de una multitud de hermanos (Rom. 8, 29), para que les congregara en una fraternidad. Todos los creyentes en Cristo (obsérvese ya cómo la Iglesia viene definida en función de la fe: fideles $=$ cre, dentes in Christo) forman una comunidad, comunidad que se realiza en el interior del ser de la Iglesia y que se refleja en su estructura visible, también en forma de comunidad, de sociedad organizada y concorde por la caridad visible.

Este cuerpo de Cristo que se adhiere a El por la fe y por los sacramentos (cfr. Lumen gentium, 7) que son los instrumentos de la comunidad de vida con Cristo y con los demás, tiene una doble vertiente en su ser: la visible y la invisible. El ser comunitario de la Iglesia se realiza en dos niveles: comunidad de realidades espirituales y comunidad sacramental de medios salvíficos. En el primer tiem- 
po de esta estructura comunitaria hay que colocar las virtudes teologales en la Iglesia :

\begin{abstract}
"Cristo, Mediador único, estableció su Iglesia santa, comunidad de fe, de esperanza y de caridad en este mundo como una trabazón visible y la mantiene constantemente, por la cual comunica a todos la verdad y la gracia. Pero la sociedad dotada de órganos jerárquicos y el cuerpo místico de Cristo, reunión visible y comunidad espiritual, la Iglesia terrestre y la Iglesia dotada de bienes celestiales, no han de considerarse como dos cosas, porque forman una realidad compleja, constituida por un elemento humano y otro divino" 19.
\end{abstract}

He ahí la densidad eclesial de las virtudes: fe-esperanza-caridad. Ellas forman algo constitutivo del ser comunitario, espiritual, invisible, interno, celeste de la Iglesia. Son el núcleo interior de su sacralidad, de su santidad: Iglesia santa igual a comunidad de fe, de esperanza y de amor. Es decir: la santidad de la Iglesia está formada por la trilogía de las virtudes teologales que le unen a Cristo no de una forma sacramental, pero sí realmente, aunque misteriosamente. $\mathrm{Y}$ esa santidad interior configurada por las tres virtudes tiene que constituir también la santidad visible porque una misma es la Iglesia y una misma es la santidad aunque tenga dos vertientes. De ahí que la vivencia social, visible y pública, en toda la comunidad eclesial, de las virtudes teologales tiene aue constituir igualmente una característica de la Iglesia de Cristo. El Concilio lo pedirá repetidamente: a los sacerdotes, a la jerarquía, a los religiosos, a los seglares. De esta forma la vida de fe, de esperanza y de caridad y su correspondiente ejercicio visible se convierte en testimonio y revelación de la razón interna del ser de la Iglesia como comunidad teologal ${ }^{20}$.

Ya es un dato que merece la pena anotarse: en las perspectivas teológicas del Concilio las virtudes teologales tienen ante todo una dimensión comunitaria y eclesial que viene así a romper con la inevitable mentalidad de que las virtudes fuesen algo que se desarrolla en el interior del hombre y sólo para él en una relación vertical para con Dios. Esto es importante frente a las exigencias de la secularización donde las virtudes dejan de ser ese (espacio sagrado) o recinto interior del hombre frente a Dios para abrirse a una concepción mu-

\footnotetext{
19. Cfr. Lumen gent. 8; LEON XIII: Sapientiae christianae. ASS, 22 (1889-90) pp. 392 ss; Satis cognitum, ASS (1895-96) 710 y 724 SS. PIO XII: Mystici corporis, AAS, 22 (1889-90) pp. 299300; Human' gęneris, AAS 42 (1950) 57.1 ss. Cfr. CH. JOURNET: Teología de la Iglesla, Desclée de Br. Bilbao 1966; pp. 22-25.

20. Cfr. entre otros, los siguientes luaares: Lumen gent. nn, 31, 41;Apost. actuositatem, nn. 3 y 4; Gaudium et spes, 48; Perfẹctae charit. 25. También los catecúmenos son ya testigos de la fe, esperanza y caridad: Ad gentes, 14.
} 
cho más social y dinámica. De tal forma que la religión, la religiosidad de nuestro tiempo consistirá en un ejercicio hacia fuera, social y visible como decíamos, del dinamismo triangular del Espíritu Santo que se despliega en el ser de las virtudes que en tanto son virtudes en cuanto son para otro y en cuanto partiendo de mí interioridad alcanzan a los demás constituyendo así, sobre todo el amor, la esencia de la religión secular en un sentido ortodoxo ${ }^{21}$.

b) Espíritu Santo y virtudes teologales.

También estas relaciones pertenecen a la visión teológica y eclesial en que nos encontramos explicando las virtudes. La Iglesia es la comunidad de fe-esperanza-caridad que la forman los que se adhieren a Cristo, los que creen, esperan y le aman. Ahora bien, esta comunidad tiene, según la teología paulina en que se mueve el Concilio, un principio vital, una Virtud en sentido personal, una dinamis y un pneuma que coinciden en el Esoíritu Santo con el que Cristo anima a su Iglesia, a sus fieles formando su Cuerpo. El Espíritu Santo es la Virtud y el Don esencial de Cristo a su Iglesia de quien proceden los demás dones y virtudes en los fieles:

"La vida de Cristo en este cuerpo se comunica a los creyen-
tes que se unen misteriosa y realmente a Cristo paciente y glo-
rificado por medio de los sacramentos... Unificando el Cuerpo,
el mismo Espíritu por sí y con su virtud y por la interna cone-
xión de los miembros produce y urge la caridad entre los fie-
les" ${ }^{22}$.

La comunidad de virtudes sólo se entiende y explica en la Iglesia a través de la unidad del Espíritu Santo como única Virtud que produce en todos los mismos sentimientos de fe-esperanza-caridad y que por eso precisamente llamamos virtudes porque son la fuerza del Cristo resucitado (L. G. n. ${ }^{\circ}$ 8: "virtute autem Domini resuscitati roboratur") y que tiene un efecto creado en la variedad de virtudes y dones con que enriquece a la Iglesia. En definitiva la diversidad de virtudes en la Iglesia son derivaciones de la presencia de Cristo en ella. El es su virtud, su fuerza, su don, su sabiduría, su esperanza, su amor. Agustín unificaba así las cosas:

\footnotetext{
21. Hemos indicado más arriba cómo no hay que tener miedo a esta religiosidad o a la piedad impuesta y exigida por la secularización. No se puede negar un mérito indiscutible a los protestantes que tanto han aportado a este equilibrio en el concepto de vida cristiana, de vida piadosa, aunque hayan llegado a exageraciones: "No se puede cerrar los ojos ante la afinidad que presentan muchas de las preocupaciones y tesis de Tillich con las de Bonhöfer y la actual teología católica. Algunos teólogos católicos hace ya cierto tiempo lo han notado refiriéndose especialmente a su teología sistemática": L. MALDONADO: Op. cit. pág. 99.

22. Lumen gentium, n. 7 .
} 


\begin{abstract}
"Después de la Ley viene la gracia, ella es la bendición. ¿Y qué auxilio nos prestó la gracia y la bendición? 'Irán de virtud en virtud'. Pues por la gracia se conceden muchas virtudes: 'A uno ciertamente se da por el Espíritu habla de sabiduría; a otro, habla de ciencia según el mismo Espíritu; a otro fe; a otro gracia de curaciones; a otros linajes de lenguas; a otro interpretación de lás mismas; a otro profecías. Muchas son las virtudes pero todas son necesarias aquí; de estas virtudes vamos a la virtud. ¿A qué virtud? A Cristo, Virtud y Sabiduría de Dios. El que concede las distintas virtudes en este mundo dará en lugar de todas las virtudes necesarias y útiles en el valle del llanto, una Virtud: a sí mismo... Estas virtudes se nos dan ahora en el valle del llanto por la gracia de Dios; y por ellas nos encaminames a aquella otra virtud" ${ }^{23}$.
\end{abstract}

Para Agustín todas las virtudes son derivación de la única Virtud que es Cristo habitando en su Iglesia como en un Templo vivo. Las virtudes teologales son algo necesario para el dinamismo de la Iglesia y su perfección: son las piedras vivas de que consta este templo espiritual que es la comunidad de los creyentes. La Iglesia se funda en la fe, se levanta en la esperanza y se perfecciona en la caridad ${ }^{24}$. El Espíritu Santo es el que difunde en la Iglesia y en nosotros las verdaderas virtudes, la única virtud o sea en la que se resumen todas: la caridad (Serm. 304, 5, 4). Las virtudes son una necesidad en la edificación, desarrollo y crecimiento de la Iglesia peregrina en la tierra que se desenvuelve entre dificultades internas y externas hasta que llegue a la fijación definitiva en la contemplación de la virtud Cristo. Las virtudes de la fe-esperanza-caridad son las paredes espirituales del templo también espiritual que es la Iglesia de Cristo donde habita el Espíritu Santo, del cual es piedra angular Cristo de donde parten y al mismo tiempo convergen todas las virtudes en la Iglesia. El es simultáneamente piedra fundamental y angular; fundamental porque cuanto más nos adherimos a $\mathrm{El}$ más fuerte es nuestro fundamento, nuestras raíces, nuestra base. $\mathrm{Y}$ angular porque cuanto más nos acercamos a El más unidos y compactos estamos entre sí, formando unidad de ser y de crecimiento en adhesión a Cristo y a los demás

23. Cfr. En. In ps. 83, 11, PL. 37, 1965-1066. El cristocentrismo de las virtudes en S. Agustin tiene dos expresiones: platónica una, la que hemos visto: de las virtudes se asciende a la Virtud que es Cristo, la suprema Virtud. Otra expresión ya propiamente cristiana representada por el texto siguiente del Sermo 144, 2, 2, PL. 38, 788: "Qui ergo in Christum credit, cretada por el texto siguiente del Sermo 144, 2, 2, PL. 38, 788: "Qui ergo in Christum in et in christum, venit in eum Christus et quodam modo unitur in eum, et membrum in corpore dendo in Christum, venit in eum Christus et quodam modo unitur in eum, et membrum in corpore a valor de la fe al lado de los sacramentos en la unión del hombre a Crid 174, 2, 2, PL. 38, 940-941; Tract. in Joan. eleva esperando, se perfecciona amando".

24. Cfr. Serm. 27, 1,1, PL. 38, 178: "Buscas qué casa: ya te lo indica el salmo: 'cantad al Señor un cántico nuevo, cantad al Señor toda la tierra'. He aquil la casa. Cuando toda la tierra canta el cántico nuevo es casa de Dios. Se edifica cantando; se fundamenta creyendo, se eleva esperando, se perfecciona amando". 
en El. Cristo es la consistencia de todas las virtudes en la Iglesia por su doble función: fundamento angular.

En la edificación de la Iglesia como cuerpo místico de Cristo y templo espiritual la fe aporta su firmeza, por la fuerza de su convicción por la que se adhiere fuertemente a Cristo. Aporta también la forma al edificio. La esperanza proporciona solidez y altura celeste a las realidades temporales. Aporta la orientación hacia arriba de las paredes: su dimensión vertical, elevación firme y serena en la función y en el ser de la Iglesia. Y por fin la caridad es la que da cohesión y fuerza a las distintas partes entre sí. Siempre, para Agustín la caridad edifica uniendo y estrechando los vínculos individuales al todo, a Cristo, que es el fundamento puesto por Dios: I Cor. 3, Io. Ir. Paradójicamente nuestro fundamento está puesto arriba y alli nos conducen las virtudes, el peso de la esperanza y de la caridad ${ }^{25}$.

Todo esto tiene lugar porque el Espíritu es siempre principio de unidad y vínculo de paz en la sociedad teologal que es la Iglesia para Agustín también, de la que es signo y expresión la unidad y la paz visible de la comunidad eclesial.

Dentro de la Iglesia hay, además de virtudes, diversidad de dones, de gracias, de ministerios. También por aquí vamos a ver la relación que existe entre las virtudes y el Esoíritu Santo. Porque así como el Espíritu lleva consigo siempre la realidad de la (dinamis) también encierra siempre el concepto de donación, de don gratuito de Dios al hombre. Del texto clásico de Rom. 5, 5 el Concilio de Trento hacía derivar estas tres dimensiones con respecto a las virtudes o realidades llamadas $\mathrm{fe}$; esperanza, caridad: infusión-donación por parte de Dios; inherencia y permanencia. Y todo ello porque es el Espíritu Santo, el Don personal del Padre, el que difunde como dones creados las virtudes que llamamos con lenguaje teológico y tradicional virtudes teologales ${ }^{26}$. Sin embargo el Concilio no entra en la distinción entre dones y virtudes. Simplemente dirá en la Cons. Dei verbum, 5 que cel Espíritu Santo perfecciona constantemente la fe con sus dones). Como se ve admite la distinción entre virtudes y dones

\footnotetext{
25. Cfr. Serm. 337, 1,1, PL. 38, 1476; Ib d. 337, 5, PL. 38, 1478

26. Dger. 800 y 821 . Un buen estudio de la doctrina de Trento sobre lo característico de las virtudes cfr. L. LENNERZ: De virtutibus theologicis, Romae 1933, 343-348 con abundante documentación en torno a los hechos que llevaron a la formulación definitiva de los textos con estas características. Cfr. etiam J. ALFARO: Fides spes, charitas (ad usum privatum). Romae 1964,618 .
} 
en sentido estricto, aunque las virtudes sean ya dones del Espíritu Santo, el primer Don y la primera Virtud ${ }^{27}$.

c) Sacramentalismo o virtudes.

Todo lo dicho sobre las virtudes en la Iglesia y su relación con el Espíritu Santo nos lleva ahora de la mano a desarrollar otro tema. Hemos visto cómo ellas formaban parte esencial del ser interior, pneumático, de la Iglesia. Los sacramentos en cambio son signos de la superficie visible y comunitaria de la Iglesia. ¿Habrá entonces una subordinación o un paralelismo entre virtudes y sacramentos? ¿Cómo entiende el Vaticano II la relación entre el sacramentalismo en la Iglesia y las virtudes? ¿Qué es el primero en la Iglesia, los sacramentos o las virtudes?

Damos por supuesto el relieve que lo sacramental va tomando en la teología y en la espiritualidad de nuestro tiempo. Lo religioso de hoy tiene que ser esencialmente sacramental. Los fenómenos religiosos no se conciben, como en épocas anteriores, en sentido de actos interiores, invisibles, imperceptibles, que se desarrollaban en las intimidades de Dios y el alma: eran más actos místicos, es decir, misterioso's y escondidos. Hoy en cambio, hemos descubierto y demostrado que todo sentimiento de religiosidad puramente interior (y aquí era donde se colocaban las virtudes teologales) carece de sentido si no tiene un antecedente sacramental, si no parte de un hecho visible $y$ palpable, o constatable por todos. Es más, toda espiritualidad o espiritualismo, toda religiosidad tiene oue ser esencialmente sacramental, es decir, desarrollarse $\mathrm{y}$ realizarse en un sacramento, en un factum externo que indique los sentimientos correspondientes. Creer hoy no es una relación puramente vertical y sontimental hacia Dios ; no es sólo la conciencia de la presencia de Dios en mí, la entrega de mi interioridad intelectual y sicológica a Dios, sino que es encontrarse con El a través de un hecho sacramental. Creer en Dios no será tanto creer o aceptar a Dios en sí, a auien no vemos, como dirá S. Iuan aplicándolo a la caridad, sino que creer es, para la teología de la seculari-

27. También en la Lumen gent. 12 encontramos una alusión a este problema. Dice el Concilio tratando de las relaciones entre Espiritu Santo y las virtudes después de haber descrito la estructura sacramental del Pueblo de Dios: "Además el mismo Espiritu Santo no solamente santifica y dirige al pueblo de Dios por los sacramentos y los ministerios y lo enriquece con las virtudes sino que distribuyéndolas a cada uno según quiere (I Cor. 12, 11) reparte entre los fieles sus dones y gracias de todo género, incluso especiales". Más adelante hablaremos de es. to. Aqui nos interesaba sólo ver cómo el Concilio distingue las virtudes de los "dones y gracias de todo género que el Espiritu Santo da a la Iglesia". 
zación, aceptar o entregarse a Dios que está presente en un sacramento, según los distintos niveles de sacramentalidad que hay en el cristianismo. Esta dimensión de visibilidad sacramental que se exige a la religiosidad de hoy, a la espiritualidad de la secularización, ¿significará una crisis para el desarrollo de las virtudes teologales como realidades sagradas e internas, o por el contrario las alcanzará también en su exigencia sacramental? "Toda pedagogía cristiana -dice Daniélou- sea cual fuere el campo en que se ejerza, debe definirse principalmente por su relación con el hecho cristiano... La fe cristiana tiene por objeto acontecimientos que son las obras divinas, es decir, las acciones de Dios en la historia. El objeto de la fe es la historia santa, es decir, la historia de las acciones divinas)" ${ }^{28}$.

Indudablemente todo esto tiene un valor. La fe de hoy, las virtudes de hoy, la piedad, la religiosidad, tiene que consistir en actuaciones sacramentales concretas. No consistirá ya en un vago sentimiento o percepción de lo sobrenatural. En tanto se es cristiano en cuanto se encuentra uno con Cristo en los sacramentos y en cuanto que de ahí parten las posturas virtuosas.

Hay en el Concilio un texto que pone orden en todo esto que estamos desarrollando. Está en la mísma línea de comunidad y de eclesialidad que decíamos antes:

"La condición saorada y orgánicamente constituida de la comunidad sacerdotal se actualiza tanto por los sacramentos como por las virtudes" ${ }^{23}$.

Según esto, la situación de sacralidad en que se encuentra la Iglesia por ser ungida y habitada por el Espíritu Santo que derrama sus dones (I Jon. 2,20-27), que la santifica por los sacramentos, constituyéndola así en comunidad sacerdotal por participación en la unción y en el sacerdocio del Verbo, se actúa dinámicamente en dos tiempos,

28. J. DANIELOU: Historia de la salvación y Liturgia, Salamanca 1967, 38-39. Y más adelante. 0 . 41. "En último término la fe se refiere no a verdades sino a realidades. El Verbo de Dios . salvador entes que revelador". Sin embarao el P. Fernández. Cuesta habla de la cride Dios es salvador entes aue revelador" sin realidades sacramentales y de su teoloqía :Cfr. I.FERNANDEZ CUESTA: Una problemática en torno al valor del siano sacramental. "Liturgia" 24 (1969), 13; IDEM: ¿Cristian smo sin ritos? "Ibid". 23 (1968), 125-157; P. VANDERGEN: La crise de la Liturgie, II "Paroisse et Liturgie" 7 (1967) 642-659.

29. Cfr. Lumeen gent. 11. También en el n. 42 al hablar de la caridad como forma común de la santidad y de su crecimiento en el cristiano se apunta primero a los sacramentos y luego al ejercicio de todas las virtudes. Aqui evidentemente se habla de las virtudes también en un dinamismo antropológico, no exento de una dimensión teologal. También en la const. sobre la Sagrada Liturgia (Sacr. Conc. 12) al hablar de la función de la Lituraia en el conjunto de la vida espiritual pide, junto con. la particıpación piadosa y activa en la Liturnia, una práctica personal de la oración y de la mortificación como complemento personal de lo que ha tenido lugar sacramentalmente en lo litúrgico. Siempre las virtudes al lado de lo sacramental en la vida espiritual. 
en dos vertientes, en dos niveles: los sacramentos, y las virtudes. Ya no hay entonces por qué temer una oposición o un desplazamiento en la Iglesia de hoy de lo sacramental y de las virtudes. Las dos realidades, sacramentos y virtudes, que son acción del Espíritu Santo en la comunidad sacerdotal y virtuosa de la Iglesia tienen perfecta armonía en la realización del ser de la Iglesia, en la vida de los fieles. Son dos realidades continuas, que se completan. Los sacramentos son la actividad del Espíritu Santo en el interior de los fieles a través de acciones sagradas, de hechos sacramentales que producen en el dinamismo del cristiano la gracia y las virtudes gue son siempre inseparables de ella (cfr. Dzg. 8oo). Las virtudes son de esta forma, los efectos teologales de los sacramentos. En este sentido son una realidad sacramental en cuanto derivadas de ellos. No hay coincidencia exacta entre sacramentos y virtudes. Los sacramentos pertenecen al momento más penetrante de la gracia desde el punto de vista de Dios: son el encuentro entre Dios y el hombre. Las virtudes en cambio son la prolongación teologal y antropológica de ese encuentro. Aquí está otro valor sacramental de las virtudes, como veremos.

Ahora estamos ya capacitados para entender mejor la relación recíproca entre los sacramentes y las virtudes que lejos de oponerse o contraponerse se completan y se exigen formando así una única realidad sagrada, sacerdotal. Diremos más claramente que toda la vida en la Iglesia, toda la vida de los cristianos, toda espiritualidad y toda piedad es a la vez y simultáneamente sacramental y virtuosas. $Y$ todo ello en doble sentido: en primer lugar los sacramentos, que son el punto de partida de toda actividad religiosa, de toda vivencia del misterio y de la intimidad con Dios porque son el encuentro con El que no falla. Como derivación de estos sacramentos tenemos las posturas cristianas internas en el hombre alcanzado por el dinamismo sacramental que llamamos virtudes. Estas virtudes tienen a su vez dos realizaciones: una teologal. de absoluta iniciativa divina, dadas a través de los sacramentos y otra antropológica, efecto de la aportación habitual del hombre que continua el compromiso y el comportamiento nacido y derivado de los sacramentos en posturas virtuosas de conducta, de pensamiento y de acción. De ahí oue todos los sacramentos tienen una virtud, una fuerza, una realidad dinámica que transmiten al que les recibe, al que se pone en contacto con Dios en ellos. Esta "virtus sacramenti) pasa a ser virtud del hombre alcanzado por los 
sacramentos. Esta virtud vendrá desarrollada por una ascesis, por una espiritualidad. Así tenemos que toda virtud es siempre derivación de la virtud sacramental y por eso mismo toda espiritualidad es, en sí misma, sacramental, en su origen y en su participación.

Paralelamente toda virtud dispone al sacramento y continúa al sacramento además de acompañarle. Las virtudes son, pues, sacramentales en un doble sentido: por su procedencia. $Y$ son sacramentales porque una vez cesado el sacramento como acto transitorio son las encargadas de proclamar en el cristiano ante el mundo que su fuerza y su virtud son una revelación sacramental, una ocasión de encuentro entre el mundo y Dios. Las virtudes del cristiano son los sacramentos antropológicos por los que los hombres verán a Cristo reflejado en ellas, y servirán también para el encuentro de Cristo con el mundo a través de la (virtus sacramenti) no en sí sino en el cristiano; porque también el cristiano, por sus virtudes se ha hecho sacramento de Cristo, ante el mundo, y como todo sacramento, tiene una (virtus).

Así es como se puede llegar a una síntesis entre la función de los sacramentos y las virtudes: se sacramentalizan las virtudes y se virtualizan los sacramentos. Es decir: los sacramentos se prolongan en las virtudes y las virtudes comienzan en los sacramentos. Los sacramentos tienden así a las virtudes: se participa de los sacramentos para ser uno mismo, por la virtudes, sacramentos ante el mundo ${ }^{30}$. Y así es como se podrá llegar también a una inteligencia o reconciliación del problema entre sacramentalismo y personalismo que preocupa en la teología de hoy: se teme que lo sacramental no sea vivido personal. mente; las virtudes serían, pues, la vivencia personal, simultánea y coexitencial a los sacramentos, de las realidades transmitidas por ellos ${ }^{31}$. No hay pues oposición entre sacramentos y virtudes; entre piedad sacramental y personal; entre espiritualidad litúrgica y subietiva. No admitimos un pansacramentalismo pero tampoco un panvirtualismo que no veía en la esviritualidad más que la labor personal de las virtudes atribuyéndolas todo lo sagrado en el hombre. Todo es sagrado en la Iglesia, en el cristiano, cuya sacralidad participada del Es-

\footnotetext{
30. Cfr. E. ONANnIA-la sacramentalidad dal criatiano, "Lituraia" 24 (10ะ0) 64-8n: InFM: Llturgia y existencia cristiana. "Liturgia" 23 (1968) 189-192; J. F. LESGRAUWAET: La Liturgla y el sentimiento vital hoy, en "Fin del cristianismo convencional" Salamanca, 1970, pp. 273-298 31. Para el problema del personalismo en teoloxia y en espiritualidad, cfr. G. GLOEGE: Der theolnnische Personalismus als doamatisches Profím, "Keriama un Doama" 1 (1955) 23 41, O. SEMMELROTH: Personalismus und Sakramentalismus, "Theolonie in Geschichte und Gegenwart". Festschrift für M. Schmaus. München 1957; pp. 199-218. IDEM, Dios y el hombre al encuentro, Madrid 1959; IDEM: El ministerio espiritual, Madrid, 1967; pp. 22-26.
} 
píritu S. por los sacramentos se continúa en las virtudes para llegar al mundo en el que el cristiano tiene que desarrollar su vida de fe. Así es como él ejerce su condición sagrada: mediante la aproximación a las virtudes que serán un reflejo de la Virtud del Espíritu Santo en la Iglesia.

Más adelante tendremos ocasión de ver cómo las virtudes teológicamente descritas hasta aquí con fórmulas teológicas, no son algo cerrado exclusivamente en lo sagrado sino que teológicamente las virtudes son algo abiertas al mundo y al testimonio. Desde ahora en adelante ya no habrá identificación entre lo teologal y lo sagrado. $\mathrm{O}$ mejor dicho todo lo teologal llevará esencialmente una dimensión al mundo y una relación con él y no sólo con Dios como se creía ver en las virtudes que por su acentuada dimensión teística se les llamaba teo-logales.

\section{PERSPECTIVAS SECULARES}

Llamamos secular a la dimensión abierta hacia el mundo que presenta la teología de las virtudes en el Concilio Vaticano II. Las hemos estudiado en su encuadre teológico: ahora vamos a verlas en su referencia secular que está implícita en la misma teología y que no es una cosa añadida o yuxtapuesta o contrapuesta. Ni la dimensión secular de las virtudes va a impedir que éstas se sigan llamando tranquilamente teologales; pero tampoco del hecho que se llamen teologales no van a estar abiertas a un dinamismo, a un ejercicio secular, es decir, sobre el mundo. Toda la reflexión conciliar sobre las virtudes está presidida por esta doble aplicación: teologal y secular; hacia Dios y hacia el mundo; religiosidad y secularidad ${ }^{32}$.

Las preguntas que nos esperan ahora son éstas ¿̇en qué relación están las virtudes con la salvación del mundo? Las virtudes son de la

32. Estamos de acuerdo con Van Leeuven cuando admite un cambio y una evolución real en la teología del Concilio que va desde la Lumen gentium hasta la Gaudium et spas. Son distintos los modos de presentar los mismos conceptos en un documento y en otro de los citados. La misma realidad de la Iglesia es presentada distintemente en la Lum. gent. y en la Gaud et spes aunque sea, como decimos, la misma lglesia, la misma salvación. Esta idea podemos aplicarla a todos los conceptos teológicos del Concilio. En la "Gaudium et spes" se presenta una salvación, una teología, una fe, más secular, más ab'o'ta al mundo más en relación y en contacto con él. La teología, las virtudes en esta vertiente, no pueden ser vistas como realidades específicamente teologales, autónomas, independientes o separadas del munđo. El punto de vista secular de la teología aparece más claro al final del Concilio en este Documento clave que parece pertenecer a otra época, a otra mentalidad, a otro lenguaje de la lglesia. Efectivamente todo se explica y aplica en función del mundo. También las virtudes. Esto es lo que haremos en la segunda parte de nuestro estudio: la dimensión secular de las virtudes entendido en este sentido correcto y ortodoxo. Cfr. P. A. VAN LEEUWEN: Salvación y mundo en el Vaticano Il, en el vol. "Fin del cristianismo convencional". Salamanca 1970; 253-272. 
Iglesia y en la Iglesia, pero la Iglesia está en el mundo y para el mundo. Lo teologal tiene que estar en función y al servicio de lo secular, de lo mundano para transformarlo y consumarlo en sentido profético, no sólo en sentido físico ${ }^{33}$. Veamos entonces cómo contribuyen las virtudes a esta salvación, santificación, transformación del mundo.

a) Virtudes y mundo secularizado.

La actitud del cristiano ante el mundo condicionada por la ausencia o por la presencia de las virtudes está, indudablemente influyendo en la configuración religiosa de este mismo mundo. Así lo expresa el Concilio: "Por lo cual, en esta génesis del ateísmo pueden tener parte no pequeña los propios creyentes, en cuanto que, con el descuido de la educación religiosa, y con la exposición inadecuada de la doctrina o incluso con los defectos de su vida religiosa, moral y social han velado más bien que revelado el genuino rostro de Dios y la religión " ${ }^{34}$. Ahí está la responsabilidad de los cristianos en la formación del ateísmo moderno. Dicha responsabilidad o aportación indirecta del creyente al ateísmo es la separación que se hace tan fácilmente entre fe y vida; entre religión interna y actuación social; entre la dimensión teologal de nuestra existencia cristiana y la dimensión mundana, social, testimonial de esa misma existencia. Esto es lo que aspecto teologal del aspecto social de las realidades religiosas, sagravemos como causa de la intensificación del ateísmo: la separación del das. En este caso de las virtudes.

Se ha hablado mucho del cristianismo anónimo en lo todavía no cristiano. La secularización trabaja mucho sobre este concepto : el cristianismo implícito que hay en tantas realidades terrenas a partir de la resurrección y de la redención de Cristo. Pero no nos damos cuenta de que esto nos obliga a otro reconocimiento doloroso que está en el reverso: si existe un cristianismo implícito también existe un ateísmo implícito. Este ateísmo implícito, virtual, es la causa de tanto

33. Hablamos de "consumar" en el sentido inicial de "perfeccionar". Para comprender la etimología y el sentido cristiano del término, nos puede ayudar muy bien la reflexión agustiniana sobre el "fin" y la "perfección" aplicado a Cristo y a un cristocentrismo cósmico como hace el Concilio, en un lenguaje bíblico: "Luego dirigid la atención al fini dirigidla a Cristo. ¿Por qué se llama fin? Porque todo lo que hacemos lo referimos a El; y cuando llegamos a El no tenemos ya otra cosa que buscar. Se llama fin la consumación y la perfección. De un modo entendemos al decir 'Se terminó el alimento que se comía' y de otro distinto cuando se dice 'Se terminó la túnica que se tejía'. En ambos casos se ha consumado. Pero el alimento se consumió y desapareció. Mas la túnica se consumó (se perfeccionó) y permanece. Luego nuestro fin debe ser nuestra perfección y nuestra perfección es Cristo. En El nos perfeccionamos porque somos miembros de su cabeza... Luego cuando oís en los salmos 'Para el fin' ... no penséis en la consumición sino en la perfección (consumación)": En. in ps. 54, 1, 1 (PL. 36, 628).

34. Cfr. Const. Gaudium et spes, n. 19. 
ateísmo abierto como encontramos en muchas vivencias de los hombres. Nos explicaremos mejor a partir de esta terminología que esperamos nos sirva.

La fe, lo religioso-cristiano, en tanto es cristiano en cuanto es testimonio. No basta con creer: hay que dar testimonio y demostrar lo que se cree. También los demonios creen, también los ateos creen, dice Agustín ${ }^{35}$. Y la fe de los cristianos tendrá que ser algo distinta a la fe de los demonios, de los ateos. La diferencia está en el testimonio de la caridad : unos creen y no aman; otros creen y aman porque hacen lo que creen poniendo la vida al servicio de la fe: es lo que 1lamamos el testimonio, ser testigos con la vida de las realidades teologales e interiores del cristianismo. Es la confessio: confesar con las obras lo que se cree interiormente. Aquí es donde descubrimos el ateísmo implícito del que hablábamos antes. Tan ateo es el que no cree como el que creyendo no da testimonio hacia el mundo de su fe. El ateísmo tiene estas dos formas : no creer y no dar testimonio de la fe. Se puede afirmar a Dios de palabra y se le puede negar con las obras: este es el ateísmo cristiano de nuestros días. También aquí nos sirve Agustín de guía:

"De qué os extrañáis si los paganos niegan que Cristo vino en carne mortal? ¿De qué os extrañáis si los judios niegan que Cristo vino en carne mortal? ¿De qué os admiráis si lo niegan también los maniqueos? Os digo a vuestra caridad que también todos los malos católicos confiesan de palabra que Cristo vino en carne pero lo niegan de hecho. No queráis, pues, estar seguros de la fe. A la fe recta tenéis que añadir la vida recta para que confeséis que Cristo vino en carne mortal: con las palabras diciendo la verdad y con los hechos viviendo rectamente. Pues si lo confesáis con las palabras y lo negáis con los hechos, la fe de esos malos católicos está muy cerca de la fe de los demonios" 36 .

35. Por su gran interés traemos aquí la reflexión agustiniana sobre estos dos aspectos de la fe para evitar posibles espejismos: la fe y su dinamismo en la caridad: "Por lo que creemos, eso es la fe. Pero debe ser una fe de los cristianos, no de los demonios, pues, como dice el apóstol Santiago, 'También los demonios creen y se estremecen' (Jac. 2,19). También los demonios dijeron a Cristo: 'Tú eres el Hijo de Dios'. Confesaban los demonios lo que no creían los hombres... Hay que distinguir, pues, la fe de los demonios de la fe de los cristianos. Hay que distinguirla claramente, diligentemente. Pues también Pedro contestó esto mismo (lo que contestaron los demonios) al Señor que le decla '¿Quién decis que soy yo? 'Tú eres Cristo, Hijo de Dios vivo' Y el Señor le dice: 'Bienaventurado tú, Simón, hilo de Jonás (Mth. 16, 15-17). Oh Señor, esto mismo te dijeron también los demonios ¿por qué ellos no son también bienaventuradós? ¿Por qué? Porque los demonios lo dijeron con temor, Pedro en cambio, con amor... Los demonios no tienen esta fe que actúa por la caridad, sino solamente los siervos de Dios, los santos de Dios": Serm. 168, 2, 2, PL. 38, 912; cfr. etiam: Serm. 183, 9, 13, PL. 38, 993.

36. Cfr. Serm. 183, 9, 13, PL. 38, 993; cfr. etiam Serm. 234, 3, PL. 38, 1116. Es conocido el lugar donde Agustín desarrolla la etimologia de "fides": $\mathrm{ff}$ (= fit) des (= dicitur) fides = fit quod dicitur: "Creer en Cristo se llama fe. Acepto lo que dices: Creer en Crstio se llama fe. Pero oye tú otro lugar de la Escritura: 'El iusto vive de la fe' (Hab. 2, 14; Rom. 1, 17). Haced la justicia, creed: el justo vive de la fe. Es difícil que viva mal el que cree bien... Se llama fe porque hace lo que dice. Cuando se dice "fides" suenan dos sílabas: la primera se refiere 
He ahí, pues, reflejada la imagen del ateísmo cristiano, es decir, de la fe de los cristianos que no va acompañada de una vida de testimonio en coherencia con la fe mental o verbal. A esto es a lo que el Concilio atribuye la causa del ateísmo explícito. Es necesario, pues, dar a lo teologal, a la creencia, una expresión correcta de cara al mundo, vivirla no sóló ante Dios sino también ante el mundo. Esta sería la más correcta vivencia del cristianismo actual.

Como contraposición tenemos el hecho de que para remediar el ateísmo abierto, el Concilio convoca a los cristianos a esta manifestación ante el mundo de la esencia teologal de las virtudes, de tal manera que éstas sean una postura y una opción también visible y constatable por parte de todos los hombres y no sólo ya por aquellos que crean. La vivencia secular (y no sólo teologal) de las virtudes se convierte así en el mejor remedio para el avance cuantitativo y cualitativo del ateísmo en nuestros días:

"El remedio del ateísmo hay que buscarlo en la exposición adecuada de la doctrina y en la integridad de vida de la Iglesia $\mathrm{y}$ de sus miembros. A la Iglesia toca hacer presentes y como visibles a Dios Padre y a su Hijo encarnado, con la contínua renovación y purificación propias bajo la guía del Espíritu Santo. Esto se logra principalmente con el testimonio de una fe viva y adulta, educada para poder percibir con lucidez las dificultades y poderlas vencer. Numerosos mártires dieron y dan preclaro testimonio de esta fe, la cual debe manifestar su fecundidad imbuyendo toda la vida, incluso la profana, de los creyentes, e impulsándoles a la justicia y el amor sobre todo respecto al necesitado. Mucho contribuye, finalmente, a esta manifestación de la presencia de Dios el amor fraterno de los fieles, que con esníritu unánime, colaboran en la fe del evangelio (Phil. 1,17) y se alzan como signo de unidad" ${ }^{37}$.

Con el ejercico de una fe viva y adulta, de cara a los acontecimientos difíciles de cada día, del mundo y luego con una integridad de vida que viene dada por la cohesión entre pensamiento y acción en la fe junto con el testimonio de la caridad fraterna entre los necesitados es como el Concilio quiere que las virtudes sean una realidad que penetre la vida profana de los fieles para transformarla.

b) La superación del dualismo.

Venimos analizando y afirmando que no existe tensión irreconciliable entre la dimensión teologal y la dimensión secular de las

al hecho; la segunda al dicho. Te pregunto si crees. Dices, Creo. Haz lo que dices y hay fe": Sarm. $49,2,2$, PL. 38,321 .

37. Const. Gaudium et spes, 21. 
virtudes: de la fe, de la esperanza y de la caridad. Este dualismo entre lo teologal y lo secular o mundano dentro de las virtudes tenía una correspondiente consecuencia dentro de la espiritualidad cristiana principalmente en la expresión seglar. La santidad del seglar se veía sólo en relación con sus tiempos teologales, es decir: parecía que sólo se santificaba en la medida que actuaba la relación con Dios en el ejercicio teologal de la fe, de la esperanza y de la caridad. Cesaba este ejercicio y entonces comenzaba la vida mundana que también habría que santificar a base de orientarla hacia Dios en su finalidad intencional. Las actividades no exclusivamente teologales, religiosas, carecian de un valor santificador propio y autónomo; sólo recibían su función santificadora por las disposiciones personales con que se acercara el individuo a ellas; pero ellas mismas no parecían tener una santidad objetiva en sí mismas. Las realidades o actividades extrateologales carecían de valor religioso y a lo más eran unos medios para santificarse. Se santificaba uno en el trabajo, en el matrimonio, en el estudio; era yo quien tenía que santificarme en un contexto profano de actividados. Pero no eran las misman actividades las que me santificaban. Todo lo más que se arriesgaba la teología o la espiritualidad era a admitir que esas actividades santificaban porque eran voluntad de Dios, expresión de ella. Entonces lo que santificaba era la voluntad de Dios y el cristiano se santificaba entregándose a las ocupaciones profesionales como voluntad de Dios. Sin embargo el Concilio ha dado un paso más adelante ${ }^{38}$.

Dentro de la eclesiología del Concilio, este enfrentamiento entre la vida cristiana, la vida estructurada por las tres virtudes teologales y la secularidad del mundo se realiza especialmente y propiamente en la vida de los seolares "de quienes es propio el carácter secular» (Lum. gent. 2I). A diferencia de la situación sacerdotal y de los religiosos, a ellos les pertenece el deber de hacer presente la fuerza del Reino de Dios en su contacto con las realidades temporales, viviendo en el siglo y del siglo, entre actividades de tipo profano. Y todo ello por vocación propia. De esta forma contribuyen a la transformación cristiana del mundo desde dentro con la vivencia de las virtudes teo-

38. Todo esto a lo que hemos aludido rápidamente forma parte de las constataciones elementales de la espiritualidad seglar. Ello ha sido el punto de partida para una reflexión responsable sobre la autonomia propia y caracteristicas independientes de la forma de santidad en el laicado. Cfr. VARIOS: Santidad y vida en el siglo, Barcelona, 1966; pp. 9 ss. K. W. TRUHLAR: L'ora dei laici, Torino 1966; pp. 25 ss. 
logales en medio de sus actividades no estrictamente teologales, es decir, profanas.

La superación del dualismo a la que hemos aludido consiste precisamente en esto: cómo unificar la traea o la actividad interna-teologal con las actividades de tipo profano, secular, mundano y encontrar así una fórmula de santidad secular que no consista en un sucederse. alternativamente las situaciones de vida religiosa y vida profana sino que todo sea religioso, santificador, santo y abierto a la santidád? La santidad de los seglares no se resigna a este dualismo: creer que la unión con Dios es incompatible con la unión con el mundo; que la convivencia teologal sea opuesta a la vivencia de las realidades netamente mundanas y que por tanto su santificación sea una alternativa, una opción contrapuesta viviendo momentos de santidad y momentos de no-santidad; actividades santas y actividades no-santas.

\section{d) Apostolado y secularidad}

El Concilio es consciente de la posibilidad de esta unificación de lo teologal y de lo secular en la realización de las virtudes y así se lo pide a los seglares: "Esta vida de unión íntima con Cristo en la Iglesia se nutre con auxilios espirituales que son comunes a todos los fieles sobre todo con la participación activa en la Sagrada Liturgia, y de tal forma los han de utilizar los seglares que, mientras cumplen debidamente las obligaciones del mundo en las circunstancias ordinarias de la vida, no separen de la propia vida la unión con Cristo sino que crezcan en ella cumpliendo su deber según la voluntad de Dioss) ${ }^{39}$. Todo ello es lo que se realiza - según el Concilio- en el concepto y en la realidad del apostolado. De tal forma que también en la vida de los seglares, lo secular y lo apostólico tienen una convergencia propia en las virtudes teologales. En la actitud apostólica es donde adquieren las virtudes, lo teologal, su dimensión secular: la estructura apostólica, secular, de toda la vida cristiana es el punto de reconciliación y la superación del dualismo querida por el Concilio y al que aludíamos más arriba. Es la fórmula clave para entender lo que veníamos explicando: la vivencia simultánea de lo teologal y de lo secular en lass virtudes cristianas. Que las virtudes también deben insertarse en una existencia cara al mundo y oue ellas no son el clásico recinto sa-

39. Decret. Apost. actuosit. 4. 
grado donde el alma entra, refugiándose, silenciosamente para actuar sus relaciones con Dios, pero el Dios invisible.

Al lado de este equilibrio de dentro a fuera, hay otro de sentido inverso: de fuera a dentro. Es decir: lo teologal, íntimo, hay que exponerlo y comprometerlo en lo secular, en lo apostólico; pero lo apostólico tampoco se realiza sin lo interior; es más comienza en ello.

Las virtudes teologales vienen presentadas por el Concilio en esta doble exigencia : de ser la realidad interna, ontológica donde comienza toda realización apostólica y secular del cristianismo en el mundo. Pero al mismo tiempo ellas tienen que ser visibles y constatables a través de una acción real en y sobre el mundo, de tal manera que si el apostolado comienza en la vivencia de la fe, de la esperanza y de la caridad, éstas tampoco son tales virtudes hasta que no llegan a este contacto con lo secular para vivificarlo a través del individuo que las vive que en este caso sirve de puente sacramental para esta trasformación de lo secular por lo teologal. «El apostolado - dice el Concilio- se ejerce en la fe, en la esperanza y en la caridad que el Espíritu Santo derrama en los corazones de todos los miembros de la Iglesia) ${ }^{40} \mathrm{~A}$ su vez la realización en la existencia secular y apostólica de compromiso con el mundo de las virtudes teologales, está exigida por esta situación de intermediarias que ocupan las virtudes: ser una realidad teologal pero puesta para vivirla secularmente, es decir, ante el mundo y para el mundo. Tan esencial es lo secular en la definición de virtud, como lo teologal. Tan esencial es el mundo como Cristo en la formación y en el dinamismo de las virtudes que es el ofrecimiento de lo divino a lo secular a través del hombre; que son la personificación de lo sacramental, o la sacramentalización de lo personal en la labor de penetrar cristianamente lo secular. Las virtudes se reciben, las da el Espíritu Santo para el servicio cristiano al mundo. $Y$ los fieles portadores de esas virtudes, de esos dones, tienen el deber de poner su realidad y su acción teologal al servicio de la cristianización del mundo, de tal forma que todo don sobrenatural, toda virtud debe ejercitarse en el mundo y para el mundo.

Esta es la dimensión secular de las virtudes teologales que veníamos buscando. El cristiano por las virtudes se convierte en otro en- 
viado al mundo por el Espíritu Santo que se las da y se las mantiene para su manifestación, como Cristo mismo fue enviado y manifestado por el Espíritu Santo. Una vivencia puramente sobrenatural de las virtudes no sería posible. Toda virtud y su respectiva vivencia o realización está condicionada por los hechos seculares, por las circunstancias mundanas del cristiano que tiene como espacio vital a Cristo, pero también al munlo: ser-en-Cristo y ser-en-el-mundo al mismo tiempo, he ahí el misterio cristiano, como el misterio de Cristo consistía en estar-en-el-Padre y estar-en-el-mundo simultáneamente.

Lo secular también va a ser motivo de ejercicio de la fe, de la espeeranzà, de la caridad. Las virtudes se alimentan no sólo de lo teologal sino también de lo secular y crecen en contacto con ello. Oigamos al Concilio: "Una vida así (de ocupaciones seculares) exige un ejercicio continuo de fe, de esperanza, de caridad) ${ }^{41}$.

Si en la historia de la teología las virtudes de la fe, esperanza, cáridad, llegaron a llamarse teologales porque tienen a Dios por origen y motivo primario, nada nos prohibe llamarlas también virtudes seculares porque tienen lo secular como objeto de su ejercicio, enriquecimiento y expansión. Habrá, pues, que acostumbrarse a valorar simultáneamente, igualmente, lo oue estas virtudes tienen de teologal y de secular, sabiendo que están equidistantes entre Dios y el mundò, entre lo teologal y lo secular que es igualmente válido en su configuración.

Según esto, la fe tendrá sentido en la medida que sea una capacidad de ver y juzgar los hechos y los acontecimientos del mundo y en el mundo a la luz de la palabra de Dios. La tarea de la fe será, por consiguiente, buscar la voluntad de Dios en los hechos y acontecimientos diarios. Verlo todo en función de Cristo, porque todo lo creado tiene una referencia a Cristo. Dar el justo valor y la justa autonomía a las realidades mundanas, para amarlas rectamente, ordena-

41. Ibjd. 4. Y más adelante concretiza este condicionamiento realizado por lo secular en las virtudes: "Este modo de vida espiritual de los seglares, debe asumir una nota peculiar del nstado de matrimonio y de familia. de solteria o de viudez. de la situación de enfermedad, de la actividad profesional o social. No descuiden, pues, el cultivo de las cualidades $y$ dotes convenientes que para ello se les han dado y el uso de los propios dones recibidos por el Espiritu Santo". He aquil un trozo conciliar que justifica y estimula la reflexión teolóaica sobre dsitintas espiritualidades. Es decir, cómo lo teologal viene condicionado por las distintas situaciones del hombre y del cristiano de donde se sirue una forma específica de vivir el cristianismo. Así se entiende hoy el problema del p'uralismo espiritual, es decir, de las distintas espiritualidades en lä Iglesia. 
damente ${ }^{42}$. He ahí la labor y la configuración de una fe al mismo tiempo sobrenatural, teologal y secular ${ }^{43}$.

La esperanza tendrá que realizarse en medio de la solicitación de los valores temporales, cuya acción sobre el hombre es real. El cristiano deberá trascender (no negar) los valores terrenos sabiendo que existe algo superior, trascendente, que le espera por encima de ellos, más allá de ellos. Y cuando los acontecimientos mundanos sean adversos, la esperanza le sostiene igualmente hasta que pasen, convencido profundamente de la transitoriedad esencial de las realidades seculares que no deja ni ilusionar ni atemorizar por lo próspero ni por lo adverso. Además la esperanza le ayudará a perfeccionar el orden temporal sabiendo que así acelera el advenimiento de lo escatológico de lo final, del reinado definitivo de Dios sobre las cosas ${ }^{4}$.

A la caridad le espera la tarea más urgente: hacer presente en un mundo secularizado la realidad y la eficacia de lo sobrenatural como algo válido para la transformación de lo visible. Le corresponde convencer a todos que el mundo hay que trasfigurarlo por la fuerza de las bienaventuranzas, que sin huir de él se va a él con contenidos distintos a los mundanos: con el amor y la fuerza de lo que no se ve, de lo sobrenatural. Viviendo la caridad que el Espíritu Santo derrama en nuestros corazones (Rom. 5,5 ) el cristiano es testigo en el mundo de un amor distinto al que el mundo suele crear y de esa forma hace presente en él el amor del Padre entre los hombres.

\section{JEsus Fernandez}

\footnotetext{
42. También tenemos un precedente de todo esto en Agustín. El luchó por definir este "ordo amoris" " valoris". Juzgar rectamente del valor de las cosas, ver el valor justo de ellas para poder amar a cada una seqún su valor: amar más lo que valga más; amar menos a lo que valga menos. La fe en este caso será la capacitación interior para discernir el valor exacto de las realidades temporales frente a Dios para poder amarlo todo ordenadamente... Cfr. J. FERNANDEZ: Santidad eclesial en S. Anustin. Estudio de la espiritualidad de la Ciudad de Dios", en Rev. Agust. de espiritualidad" 8 (1967)

43. Otros aspectos seculares de la fe se encuentran en la Lumen gentium, 48: ella deberá iluminar el misterio de la existencia terrena del hombre: "Por la fe somos instrifidos acerca del sentido de nuestra vida temporal". También acerca del plan divino sobre la historia: Gaud. et spes, 15; o sobre el misterio de la muerte y del porvenir definitivo del hombre: Gaud et spes, 18: "La fe por consiguiente, apoyada en sólidas razones está en condiciones de dar a todo hombre reflexivo la respuesta al angustioso problema sobre su porvenir".

44. Cfr. Gaud. et spes, n. 21: "La Iglesia enseña además, que la importancia de los bienes terrenos no se disminuye por la esperanza del más allá, sino que más bien se robustece con nuevos motivos. Por el contrario si este fundamento divino y la esperanza de la vida eterna desaparecen, la dignidad del hombre sufre gravisimas lesiones, como tantas veces hov se deja ver, y los enigmas de la vida y de la muerte, de la culpa y del dolor quedan sin solúción, de modo que no raras veces el hombre cae en la desesperación".
} 